\title{
Long-term follow-up of acute multifocal posterior placoid pigment epitheliopathy
}

\author{
DAVID F WILLIAMS AND WILLIAM F MIELER
}

From the Department of Ophthalmology, Medical College of Wisconsin, Milwaukee, Wiconsin, USA

SUMMARY Eleven patients with acute multifocal posterior placoid pigment epitheliopathy were followed up for 47 to 175 months (mean 106 months). Seven of 18 affected eyes (39\%) developed progressive mild alterations in the retinal pigment epithelium. Seventeen eyes $(94 \%)$ had a final visual acuity of $20 / 30$ or better. One eye with progressive retinal pigment atrophy involving the fovea lost visual acuity from $20 / 25$ to $20 / 60$.

Acute multifocal posterior placoid pigment epitheliopathy (AMPPPE) was first described by Gass in 1968.' Since then there have been many reports describing its appearance, associated manifestations, course and prognosis. ${ }^{2-1 \times}$ But there have been few long-term follow-up studies performed. ${ }^{19-21}$ While these have primarily emphasised the long-term visual outcome, one study reported the development of widespread chorioretinal atrophy and associated visual loss in several patients."

The purpose of this report is to provide a long-term follow-up of patients with AMPPPE, with special emphasis on the development of any progressive fundus changes and the effect of such changes on visual outcome.

\section{Patients and methods}

Patients with a diagnosis of AMPPPE were identified from the clinic and photography records of the retina service at the Eye Institute of the Medical College of Wisconsin. The patient's history and details of the initial ophthalmic examination were reviewed. Fundus photographs and the fluorescein angiogram were reviewed to confirm the clinical diagnosis of AMPPPE. Diagnostic criteria included the presence of multifocal placoid lesions affecting the retinal pigment epithelium or choroid that blocked chor-

Correspondence to William F Mieler, MD. Department of Ophthalmology, Medical College of Wisconsin, 8700 West Winconsin Avenue. Milwaukee, Wisconsin 53226, USA. oidal fluorescence in the early phase of the fluorescein angiogram and stained in later phases. All patients thus identified were contacted and asked to return for a follow-up examination.

Follow-up data included the history of the initial episode as well as subsequent ocular history, especially symptoms suggestive of changes in visual acuity and recurrent episodes of ocular inflammation. All patients had best corrected Snellen visual acuity measurements, Amsler grid testing, and pupillary examination. Slit-lamp biomicroscopy, applanation tonometry, and fundus biomicroscopy were also done as well as binocular indirect ophthalmoscopy. The patients then underwent fundus photography and fluorescein anigiography.

The details of the follow-up ophthalmic examination were recorded, and detailed comparisons of the initial and follow-up fundus photographs and fluorescein angiograms were made. Special attention was paid to any historical evidence suggesting recurrent disease and to changes in fundus appearance suggesting progression of scarring or retinal pigment epithelial atrophy.

\section{Results}

Eleven patients with a clinical history and fundus features consistent with AMPPPE were initially seen between September 1971 and February 1981. Six were male $(55 \%)$ five female $(45 \%)$; they ranged in age from 20 to 45 years (mean 31 years, median 29 years) at the time of initial examination. The duration 
Table 1 Patient data

\begin{tabular}{|c|c|c|c|c|c|c|c|c|c|}
\hline \multirow{2}{*}{$\begin{array}{l}\text { Case/sex/age } \\
\text { (yr) }\end{array}$} & \multirow{2}{*}{$\begin{array}{l}\text { Eye } \\
\text { involved }\end{array}$} & \multirow[t]{2}{*}{ Simptomatic } & \multicolumn{2}{|c|}{ Visual acuity } & \multirow[t]{2}{*}{ Prodrome } & \multirow{2}{*}{$\begin{array}{l}\text { Foveal } \\
\text { involvement }\end{array}$} & \multirow{2}{*}{$\begin{array}{l}\text { Concurrent } \\
\text { disease }\end{array}$} & \multirow{2}{*}{$\begin{array}{l}\text { Follow-up) } \\
\text { (mo) }\end{array}$} & \multirow{2}{*}{$\begin{array}{l}\text { Progressive } \\
\text { pigment } \\
\text { atrophy }\end{array}$} \\
\hline & & & Initial & Final & & & & & \\
\hline \multirow[t]{2}{*}{$1 / F / 44$} & OI) & Yes & $2(1) / 25$ & $2(0 / 20)$ & - & - & - & 175 & - \\
\hline & OS & - & $20 / 20$ & $2(0 / 20)$ & & - & - & - & - \\
\hline \multirow[t]{2}{*}{ 2/M/20) } & OD & Yes & $20 / 25$ & $20 / 15$ & - & Yes & - & 151 & - \\
\hline & $\mathrm{OS}$ & Yes & $20 / 20$ & $10 / 15$ & & - & - & - & Yes \\
\hline $3 / F / 27$ & OS & Yes & $2(0 / 50)$ & $2(0 / 20$ & - & Yes & - & 138 & - \\
\hline \multirow[t]{2}{*}{ 4/M/29) } & OI) & Yes & $2(0 / 60)$ & $2(1 / 25$ & Viral & Yes & - & 126 & Yes \\
\hline & OS & Yes & $2(0 / 30)$ & $20 / 25$ & & Yes & - & - & - \\
\hline \multirow[t]{2}{*}{$5 / \mathrm{M} / 24$} & OI) & Yes & $20 / 25$ & $20 / 20$ & - & Yes & - & 116 & - \\
\hline & OS & Yes & $2(0 / 30)$ & $20 / 20$ & & Yes & - & - & - \\
\hline \multirow[t]{2}{*}{$6 / \mathrm{M} / 24$} & OI) & Yes & $2(0 / 20)$ & $2(1) / 30$ & Viral & Yes & Uveitis & 97 & - \\
\hline & $\mathrm{OS}$ & Yes & $2(0 / 200)$ & $2(1) / 20$ & & Yes & Uveitis & - & - \\
\hline \multirow[t]{2}{*}{$7 / F / 26$} & OI) & Yes & $20 / 40$ & $2(1 / 20)$ & - & Yes & - & 9() & Yes \\
\hline & OS & - & $20 / 20$ & $2(1) / 20$ & & - & - & - & Yes \\
\hline $8 / \mathrm{M} / 40$ & OS & Yes & $20 / 25$ & $20 / 60)$ & - & Yes & - & 88 & Yes \\
\hline $9 / F / 34$ & OI) & Yes & $20 / 30$ & $2(0 / 30)$ & - & Yes & - & 54 & Yes \\
\hline $10 / F / 34$ & OS & Yes & $\mathrm{CF}$ & $20 / 25$ & - & Yes & - & 47 & Yes \\
\hline \multirow[t]{2}{*}{$11 / \mathrm{M} / 31$} & $\mathrm{OI})$ & Yes & $20 / 20$ & $20 / 20$ & Viral & Yes & Uveitis & 47 & - \\
\hline & OS & Yes & $20 / 40$ & $20 / 20$ & & Yes & Ureitis & - & - \\
\hline
\end{tabular}

of follow-up ranged from 47 to 175 months (mean 106 months). All patients who returned for follow-up examination did so only at our request. None had a recent history of new visual symptoms. Patient data are shown in Table 1 .

The presenting symptom in all 11 patients was decreased visual acuity. The duration of ocular symptoms ranged from two days to eight months. Five patients had symptoms bilaterally (45\%) and six unilaterally $(55 \%)$. On examination, however, two patients with unilateral symptoms were found to have lesions bilaterally. Thus of 18 clinically affected eyes $16(89 \%)$ were symptomatic and two were asymptomatic $(11 \%)$.

Of 11 patients only three had a definite prodromal illness associated with the onset of visual symptoms, consisting of a generalised virus-type syndrome. No patient had taken antimicrobial agents.

The range of initial and final visual acuities are shown in Table 2. Eleven of 18 affected eyes $(61 \%)$ had an initial visual acuity of $20 / 15$ to $20 / 30$, while

Table 2 Range of initial and final visual acuities (18 eyes)

\begin{tabular}{|c|c|c|}
\hline Visual acuity. & $\begin{array}{l}\text { Initial } \\
\text { No. }\left("{ }_{0}\right)\end{array}$ & $\begin{array}{l}\text { Final } \\
\text { No. }(\%,)\end{array}$ \\
\hline $2(0 / 15-20 / 20$ & $+\quad(22)$ & $12 \quad(67)$ \\
\hline $2(0 / 25-2() / 30$ & $7 \quad(39)$ & $5(28)$ \\
\hline $2(0 / 40-20 / 60$ & $+\quad(22)$ & $1 \quad(5)$ \\
\hline $2(0 / 70-20 / 100$ & () $\quad(0)$ & () (0) \\
\hline $20 / 20()-20 / 4(0)$ & $2 \quad(11)$ & () ((1) \\
\hline CF-HM & $1 \quad(6)$ & () (1) \\
\hline
\end{tabular}

$\mathrm{CF}=$ Counting fingers. $\mathrm{HM}=$ hand movements. seven eyes $(39 \%)$ had visual acuities ranging from 20/40 to hand movements (HM). At final follow-up 17 eyes $(94 \%)$ had visual acuities of $20 / 15$ to $20 / 30$, and one eye $(6 \%)$ had visual acuity of $20 / 60$. In 17 eyes the final visual acuity was unchanged or improved in comparison with the initial visual acuity. One eye lost visual acuity from $20 / 25$ to $20 / 60$.

None of the 11 patients had a history of previous ocular disease. At the initial ophthalmic examination two patients with bilateral AMPPPE lesions had concurrent bilateral mild uveitis, one with cells only in the aqueous and one with vitreous cells also. All patients had typical creamy white placoid lesions at the level of the retinal pigment epithelium or choriocapillaris demonstrated on fundus photography and fluorescein angiography (Figs. 1A, B, C). In four patients the lesions were acute, with no evidence of early pigmentary changes. Six patients had subacute lesions, with early pigmentary changes in addition to the typical creamy white placoid lesions. One patient had an eight-month history of visual symptoms and appeared to have acute lesions superimposed on chronic pigment epithelial changes. This may have represented a recurrence of AMPPPE.

At final follow-up examination seven eyes $(39 \%)$ in six patients had developed progressive retinal pigment epithelial alterations. In one patient there were enlarged areas of abnormal retinal pigment epithelium surrounding some of the original lesions. These lesions blocked fluorescence in the fluorescein angiogram (Figs. 2A, B, C, D). One patient had progressive atrophy of pigment epithelium that was subtle but sharply defined and occurred contiguous to the originally involved areas. Four patients developed 


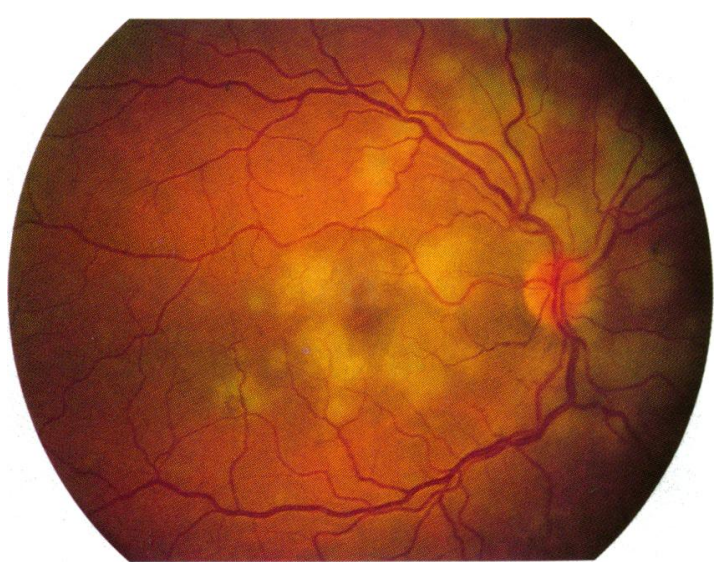

Fig. IA

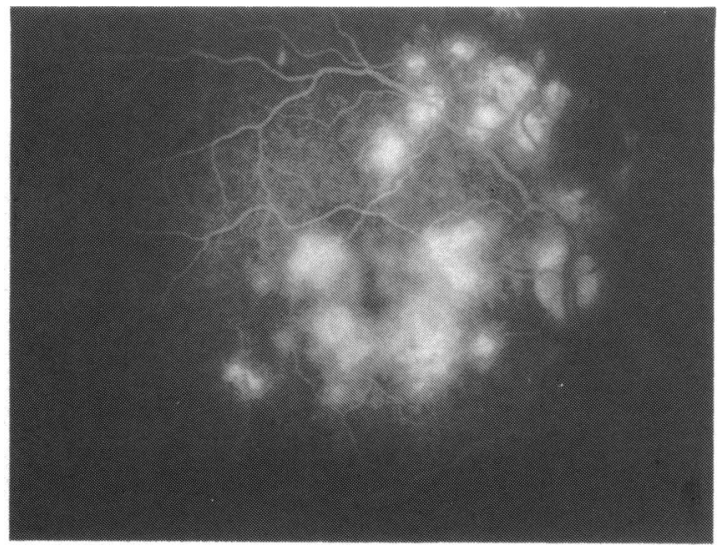

Fig. 1C

mild, more diffuse atrophy of the pigment epithelium which involved a larger area and was not always contiguous with the previous atrophic areas (Figs. $3 \mathrm{~A}, \mathrm{~B}, \mathrm{C}, \mathrm{D})$. In one of these patients the fovea was involved, with a loss of vision from $20 / 25$ to $20 / 60$.

\section{Discussion}

Acute multifocal posterior placoid pigment epitheliopathy (AMPPPE) was first described in 1968 by Gass,' who reported on three young female patients with bilateral 'rapid loss of central visual acuity secondary to multifocal, yellow-white, placoid lesions at the level of the pigment epithelium and choroid.' The lesions were noted to 'resolve rapidly, leaving permanent alterations in the pigment epithelium and minimal damage to the adjacent choroid and retina.' Vision improved markedly with resolution of the acute lesions and continued to improve for several weeks or months thereafter, such

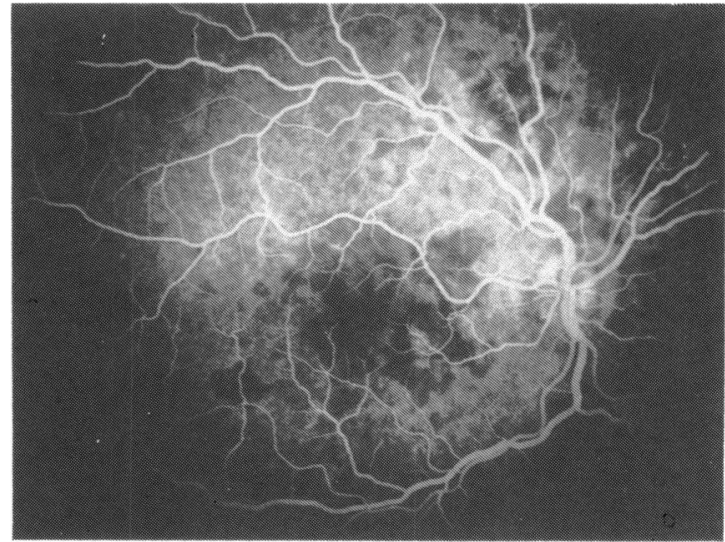

Fig. 1B

Fig. 1 A. Fundus photograph of typical AMPPPE lesions (case II). Note multifocal placoid areas of creamy-white opacification of the retinal pigment epithelitum. B. Mid-phase' of fluorescein angiogram. The acute lesions are hypofluorescent. C. Late phase of fluorescein angiogram. The lesions stain with fluorescein.

that the visual prognosis was thought to be relatively good. Since this initial description AMPPPE has also been reported to occur unilaterally in both sexes and in blacks as well as whites. 2 Many associated ocular findings have been reported, including anterior and posterior uveitis, ${ }^{2 \times}$ retinal vasculitis and papillitis, " serous retinal detachment, '? retinal oedema and superficial retinal haemorrhages, '- Marcus-Gunn pupil, ${ }^{18}$ and episcleritis.' Systemic findings have included erythema nodosum, ${ }^{\gamma \times}$ cerebrospinal fluid abnormalities, ${ }^{15}$ in cerebral vasculitis," and homonymous hemianopia. ${ }^{17}$

The anatomical site of primary involvement in AMPPPE is controversial. Some authors have favoured the retinal pigment epithelium, ${ }^{2-5}$ while others postulate the choriocapillaris.2(-11) Several reports have documented abnormal choroidal perfusion in AMPPPE, ${ }^{(2-1)}$ supporting the choroid as the primary site of involvement.

The aetiology of AMPPPE is unknown. The 

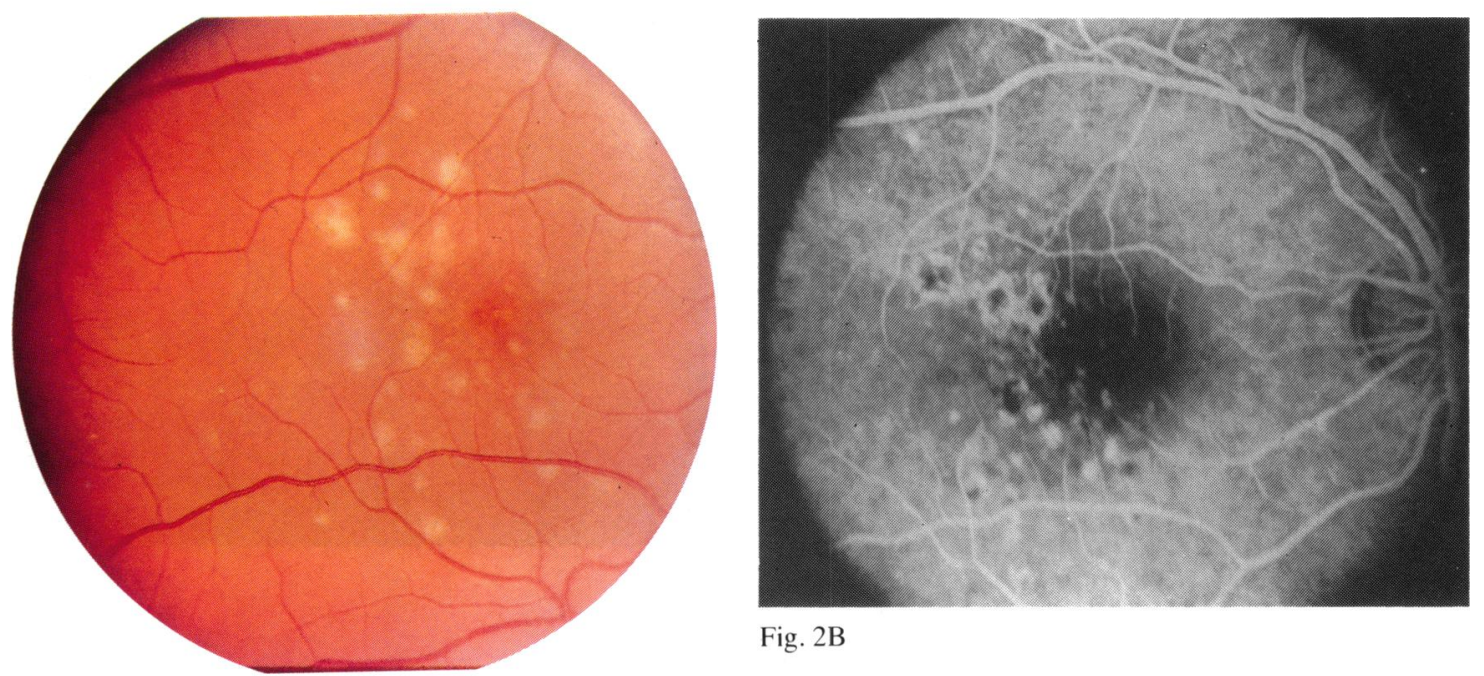

Fig. 2B

Fig. 2A

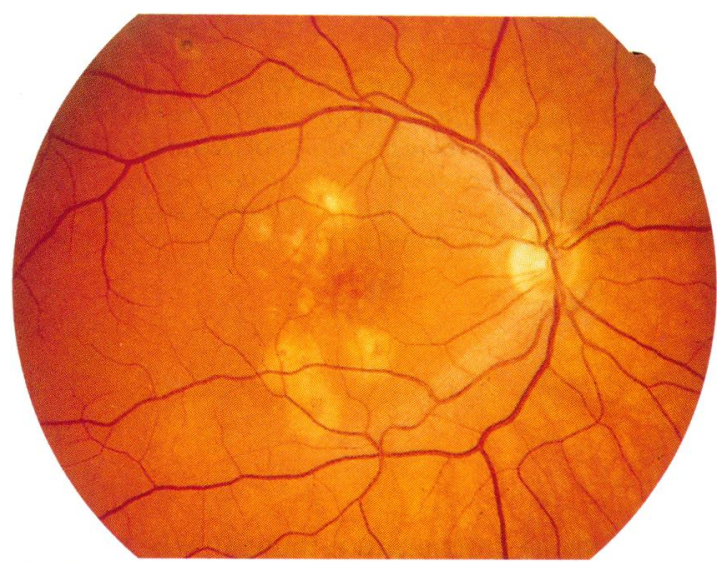

Fig. 2C

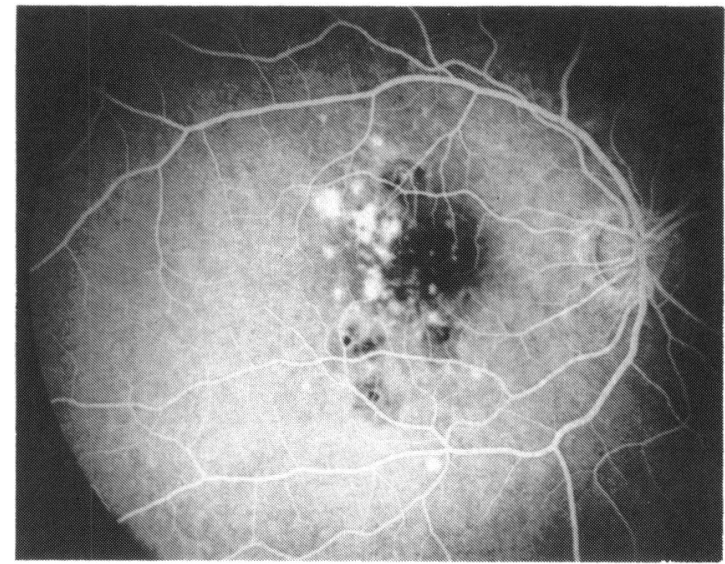

Fig. 2D

Fig. 2 A. Case 7. Fundus photograph of initial AMPPPE lesions. Arrow indicates a lesion which had enlarged at the followup examination. B. Initial fluorescein angiogram. C. Fundus appearance 90 months after initial examination. Note enlargement of areas of affected pigment epithelium. D. Fluorescein angiogram demonstrates blocking of fluorescence by enlarged areas of abnormal pigment epithelium.

possibility of an infectious cause is supported by the frequent occurrence of an antecedent viral illness. ${ }^{236 \times}$ One report also documented an adenovirus type 5 infection in association with AMPPPE. ${ }^{1 .}$ Others have suggested that microbial toxins or antimicrobial agents $^{1+}$ may elicit a hypersensitivity reaction with associated choroidal vasculitis. This may explain recurrences of AMPPPE.

The visual prognosis in AMPPPE is good, with recovery of normal or near normal visual acuity in most patients ${ }^{1-3413}$ within a few months of onset. Long-term follow-up studies have substantiated the generally favourable visual prognosis, ${ }^{14}$ though recurrent disease has been shown to result sometimes in poor visual acuity. ${ }^{1+21}$ Damato and associates ${ }^{21}$ reported on a series of patients with apparent AMPPPE of whom some developed progressive and extensive chorioretinal atrophy with associated visual loss.

In our series of patients the average duration of follow-up was 106 months. Seventeen of 18 affected eyes in patients with AMPPPE had a final visual acuity of 20/30 or better, thus also demonstrating a favourable long-term prognosis. However, seven 


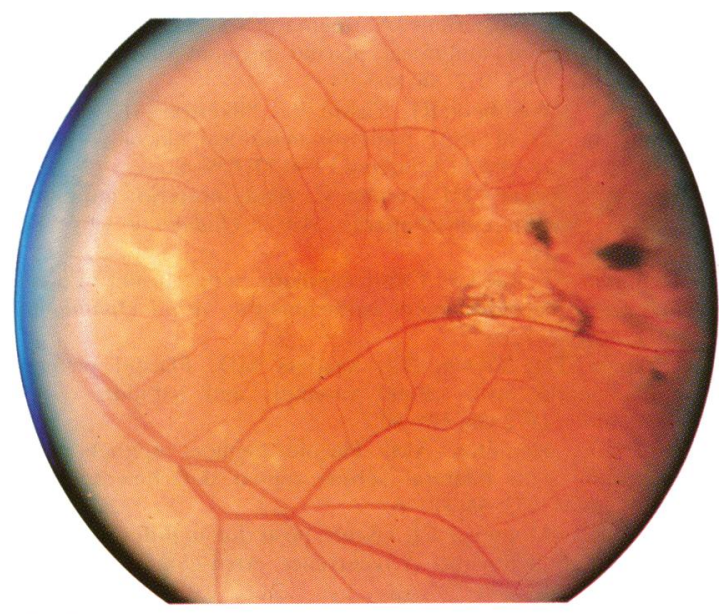

Fig. 3A

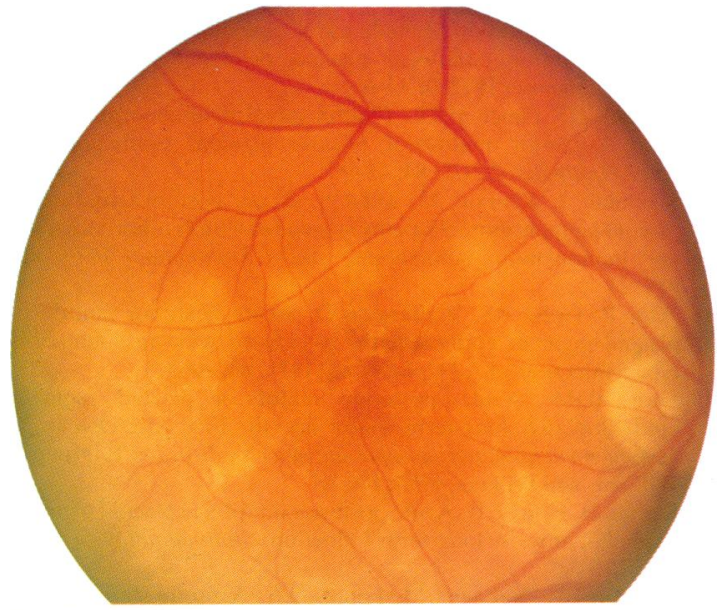

Fig. 3C

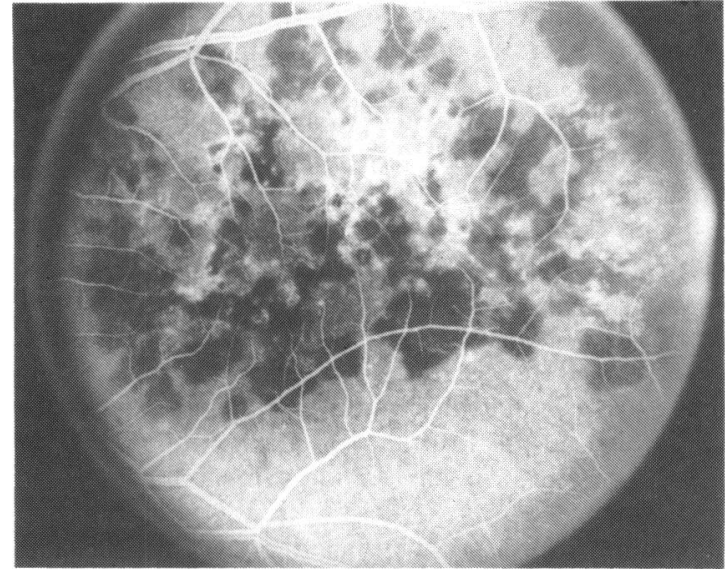

Fig. 3B

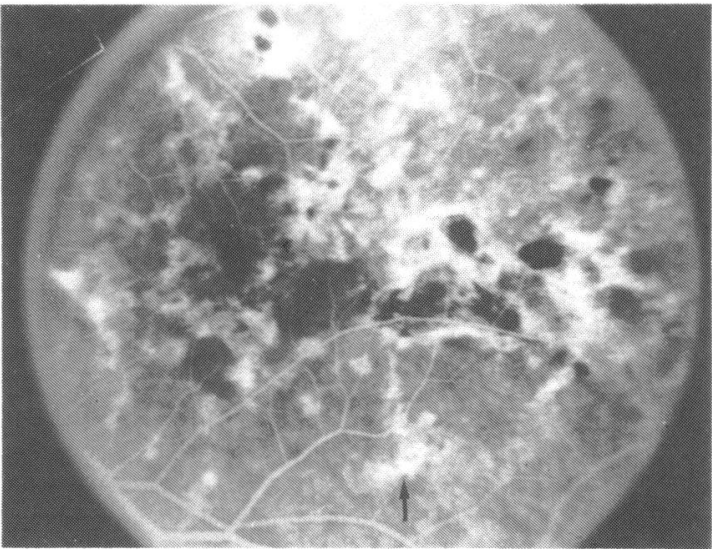

Fig. 3D

Fig. 3 A. Case 10. Fundus photograph of initial AMPPPE lesions. Note extent of lesions inferotemporal to fovea. B. Initial fluorescein angiogram. C. Fundus appearance 47 months after initial examination. Note new area of pigment epithelial atrophy. D. Fluorescein angiogram demonstrates new pigment epithelial atrophy (arrow).

eyes in six patients had progressive pigment epithelial alterations on fluorescein angiogaphy. In contrast to the report by Damato and associates ${ }^{-1}$ the progressive changes in our patients were generally subtle and assumed two forms. In two patients (two eyes) pigment epithelial alterations occurred at the margins of the initial area of pigment epithelial involvement. In one of these eyes enlarged areas of abnormal pigment epithelium blocked fluorescence (Fig. 2). In the other some of the original areas of atrophy had enlarged. In four patients (five eyes) mild, more diffuse atrophy of pigment epithelium occurred near to but not always contiguous with the original areas of involvement (Fig. 3). In one of the last group of patients the area of atrophy involved the fovea, with a decrease in vision from 20/25 to 20/60. Whether the progressive alterations occurred in retinal pigment epithelial cells which were subclinically affected during the initial episode of AMPPPE or as a result of an ongoing active process or recurrence is unknown. However, that no patient had a clinical history suggestive of recurrent or ongoing active disease suggests the former may be more likely.

The differential diagnosis of AMPPPE includes serpiginous choroidopathy, diffuse unilateral subacute neuroretinitis, multifocal evanescent white dot syndrome, vitiliginous choroiditis, and acute retinal 
pigment epithelitis." AMPPPE is a polymorphic disorder, as shown by the occurrence of a variety of associated ocular and systemic manifestations as well as a wide range in severity and extent of fundus involvement. This polymorphism may make distinction between AMPPPE and related clinical entities difficult. This was illustrated by Wright, Bird, and Hamilton, ${ }^{3.3}$ who described a continous spectrum of disease from AMPPPE to Harada's disease and emphasised the difficulties in identifying specific diseases within this spectrum. They postulated that these diseases had in common abnormal choroidal perfusion and focal retinal pigment epithelial infarction. Other authors have made similar observations and suggested that diseases within this spectrum are all manifestations of varying degrees of choroidal ischaemia. ${ }^{2+25}$

This concept may explain the differences in the presence and extent of choroidal and pigment epithelial atrophy in our series of patients in contrast to those of Damato and associates. ${ }^{21}$ Presumably eyes with extensive atrophy suffered more severe choroidal ischaemia than eyes with no or only mild atrophy. Whether eyes that suffer severe visual loss or extensive atrophy and scarring should be considered to have AMPPPE as defined by Gass' is not clear. Using the concept of a spectrum of diseases with a common underlying pathogenesis of varying severity may avoid the uncertainties inherent in rigid definitions.

\section{References}

1 Gass JDM. Acute posterior multifocal placoid pigment epitheliopathy. Arch Ophthalmol 1968: 80: 177-85.

2 Annesley WH. Tamer TL. Shields JA. Multifocal placoid pigment epitheliopathy. Am.J Ophthalmol 1973; 76: 511-8.

3 Ryan SJ, Maumenee AE. Acute posterior multifocal placoid pigment epitheliopathy. Am J Ophthalmol 1972: 74: 1066-74.

4 Fishman GA. Rabb MF. Kaplan J. Acute posterior multifocal placoid pigment epitheliopathy. Arch Ophthalmol 1974: 92: $173-7$.

5 Smith VC, Pokarny J, Ernest JT, Starr SJ. Visual function in acute posterior multifocal placoid pigment epitheliopathy. Am J Opthalmol 1978; 85: 192-9.

6 Van Buskirk EM, Lessell S. Friedman E. Pigmentary epitheliopathy and erythema nodosum. Arch Ophthalmol 1971: 85: $369-72$.
7 Deutman AF. Oosterhuis JA, Boen-Tan TN, Aan De Kerk AL. Acute posterior multifocal placoid pigment epitheliopathy. Br.J Ophthalmol 1972: 56: 86.3-74.

8 Savino PJ. Weinberg RJ. Yassin JG, Pilkerton AR. Diverse manifestations of acute posterior multifocal placoid pigment epitheliopathy. Am J Opthalmol 1974: 77: 659-62.

9 Holt WS, Regan CDJ. Trempe C. Acute posterior multifocal placoid pigment epitheliopathy. Am J Opthalmol 1976: 81: $403-12$.

10) Deutman AF, Lion F. Choriocapillaris nonperfusion in acute multifocal placoid pigment epitheliopathy. Am J Ophthalmol 1977: 84: 6.52-7.

11 Kirkham TH. Ffytche TJ. Sanders MD. Placoid pigment epitheliopathy with retinal vasculitis and papillitis. $\mathrm{Br} J$ Ophthalmol 1972: 56: 575-80.

12 Bird AC. Hamilton AM. Placoid pigment epitheliopathy presenting with bilateral serous retinal detachment. $\mathrm{Br} J$ Ophthalmol 1972: 56: 881-6.

13 Lewis RA. Montenyi Cl. Acute posterior multifocal placoid pigment epitheliopathy. A recurrence. Arch Ophthalmol 1975 93: $235-8$.

14 Lyness AL. Bird AC. Recurrences of acute posterior multifocal placoid pigment epitheliopathy. Am J Ophthalmol 1984: 98: 203.7.

15 Fishman GA, Baskin M. Jednack N. Spinal fluid pleocytosis in acute posterior multifocal placoid pigment epitheliopathy. Ann Ophthalmol 1977: 9: 33-6.

16 Bullock JD. Fletcher RL. Cerebrospinal fluid abnormalities in acute posterior multifocal placoid pigment epitheliopathy. Am J Ophthalmol 1977: 84: 4.5-9.

17 Sigelman J. Behrans M. Hilal S. Acute posterior multifocal placoid pigment epitheliopathy associated with cerebral vasculitis and homonymous hemianopia. Am J Ophthalmol 1979: 88: 919-24.

18 Azar P, Gohd RS, Walterman D. Acute posterior multifocal placoid pigment epitheliopathy associated with an adenovirus type 5 infection. Am J Ophthalmol 1975; 80: 10(1)3-5.

19 Gass JDM. Acute posterior multifocal placoid pigment epitheliopathy: long-term follow-up. In: Fine SL. Owens L. Management of retinal vascular and macular disorder. Baltimore: Williams and Wilkins. 1983: 176-81.

20 Saraux H. Pelosse B. Acute posterior multifocal placoid pigment epitheliopathy. A long-term follow-up. Ophthalmologica 1987; 194: $161-3$.

21 Damato BE, Nanjiana M. Foulds WS. Acute posterior multifocal placoid pigment epitheliopathy. A follow-up study. Trans Ophthalmol Soc UK 1983; 103: 517-22.

22 Gass JDM. Stereoscopic atlas of macular diseases. Diagnosis and treatment. St Louis: Mosby, 1987: 504-10.

23 Wright BE. Bird AC, Hamilton AM. Placoid pigment epitheliopathy and Harada's disease. BrJ Ophthalmol 1978: 62: 6(19-21.

24 Young NJA. Bird AC, Sehmi K. Pigment epithelial diseases with abnormal choroidal perfusion. Am J Ophthalmol 1980; 90: $607-18$.

25 Gaudrie A, Coscas G, Bird AC. Choroidal ischemia. Am J Ophthalmol 1982: 94: 489-98.

Accepted for publication 16 June 1989. 